\title{
A PESQUISA EM LITERATURA \\ E OS PROCESSOS DE CONSTRUÇÃO DA MEMÓRIA
}

Luiz Cláudio Vieira de Oliveira Universidade Federal de Minas Gerais

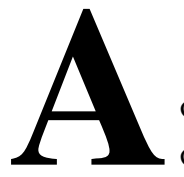

principal característica da atividade de pesquisa é seu caráter paradoxal, aquilo que Gilles Deleuze ${ }^{1}$ chamaria de dupla direção, avançando simultaneamente em direção ao futuro e ao passado: "... a potência do paradoxo não consiste absolutamente em seguir a outra direção, mas em mostrar que o sentido toma sempre os dois sentidos ao mesmo tempo." Para se avançar é necessário que se volte atrás, capturando tudo aquilo que não foi ainda abarcado pelo meu olhar. Existe um aspecto prospectivo e um aspecto retrospectivo. É preciso que o pesquisador se volte e construa o objeto sobre o qual vai lançar seu olhar. Essa construção do objeto de análise se fará como um sistema semiótico segundo ou terciário, uma vez que incidirá não mais sobre o continuum da natureza, mas sobre sistemas semióticos primários ou secundários como o sistema da língua ou o sistema literário. A cultura se produz como sistemas de signos que se sobrepõem e se imbricam, à maneira de um palimpsesto, cujas várias linguagens perdem a própria temporalidade para assumir a dos textos anteriores ou posteriores. Por outro lado, cada cultura é datada: vivencia sua época sem, aparentemente, se preocupar com passado ou com o futuro. Cada sincronia é permeada por signos oriundos de outras épocas, criando um relevo acidentado que não se pode nunca nivelar ou desdenhar. Nossa própria sincronia só pode ser vivida como uma referência

${ }^{1}$ DELEUZE, 1974, p. 79. 
permanente a outras épocas, outras linguagens que, apesar de desaparecidas há muito, ainda sobrevivem pela nossa memória.

Toda a atividade cultural do homem, desde que passou a reconhecer e a produzir signos, se resume em armazenar esses signos como condição para a criação de outros novos signos. Umberto Eco, ${ }^{2}$ no início de seu Tratado Geral de Semiótica, nos fala do sistema de significação e do processo de comunicação, em que teoriza sobre o surgimento e a transmissão de signos, ou seja, a sua ocorrência num nível de manifestação fenomenológica, o seu reconhecimento em novas ocorrências, possibilitado dela identificação de uma função e o agrupamento dessas ocorrências e suas funções em tipos mais gerais. Só muito mais tarde é que esses tipos poderão ser identificados como referentes e se transformarem em palavras, o signo lingüístico corrente. Todo esse processo semiótico pode ser visualizado na cena inicial do filme de Stanley Kubrick 2001 - Uma odisséia no espaço em que o macaco ou hominídeo, líder de seu grupo, descobre uma ossada e a usa como arma. Tal achado desencadeia o processo semiótico cultural do ser humano, de criação e de armazenamento de signos, que se concretiza quando o hominídeo joga a ossada para o alto, imprimindo-lhe uma rotatividade crescente até ela se transformar numa nave espacial.

Pela metáfora da ossada girando no ar, vertiginosamente, evidenciou-se uma linha semiótica evolutiva não no sentido biológico da palavra desde esse macaco até a nave, que só se fez possível porque cada signo criado foi responsável pela criação de novos signos, num processo contínuo de estabelecimento de relações e transformações, de manutenção de sentidos e mudanças. Toda forma de cultura só pode ser compreendida nesse sentido de acumulação e mudança, sejam quais forem os processos usados para isso. Nas sociedades ditas primitivas, são os mais velhos os responsáveis pelo conhecimento acumulado, guardando-o na

${ }^{2}$ ECO, 1980, p. 16-23. 
memória e transmitindo-o, sob forma oral, aos mais jovens. Nas sociedades letradas, cujo acervo de informações foi sempre crescente e cada vez mais diversificado, houve necessidade de se lançar mão de instrumentos auxiliares da memória. O livro, sob suas várias formas, nas várias civilizações, e as bibliotecas, desde a Biblioteca de Alexandria até as bibliotecas virtuais de nossos dias, se empenharam em guardar as informações e em repassá-las a quem quisesse fazer uso delas. Hoje já se trabalha com a noção de hipertexto, cujo conceito presume a aceleração e a otimização de um volume de informações cada vez maior. O conceito de livro, frente a outros sistemas semióticos que combinam a escrita e a imagem, também mudou. Não se pode esperar que nossos filhos leiam como nós aprendemos a ler e como sempre compreendemos a leitura: apenas como a decifração de caracteres impressos sobre uma folha. A leitura, hoje, exige uma interdisciplinaridade semiótica, uma vez que esses caracteres escritos não são mais os únicos: eles se combinam com imagens, gráficos, cores, sons, diagramas de toda ordem, símbolos das mais variadas procedências. A cultura e sua transmissão não se fazem mais numa única direção, seguindo a linha do tempo, definindo-se como uma sucessão mecanicista de causas e efeitos. A melhor representação para a forma que assumem hoje é a de um feixe de linhas divergentes; da extremidade de cada linha surge um novo feixe de linhas, e assim sucessivamente. No decorrer dos tempos, preocupou-se com o contrário. A memória deveria ser a guardiã do centro, qualquer que tenha sido ele: a Idéia, Deus, o Homem, a Ciência. Nesse caso, a metáfora desse processo deveria ser a de um feixe de linhas convergentes para esse ponto central, constituindo um sistema fechado, conservador.

Na Grécia, havia o culto a Mnemósine, a deusa da memória, porque somente ela era capaz de resgatar do esquecimento e de nomear, ou seja, de assegurar a existência dos seres e das coisas ao transformá-los em signos. Assim, a palavra tinha uma função sagrada porque era a partir dela que o mundo se fazia. Nomear era presentificar, fazer, constituir, sacralizar, distinguir algo do informe que estava além, ou aquém, dos signos. Nesse instante, a palavra, 
o signo verbal, tinha uma relação muito forte com a verdade, como no momento de criação do mundo, segundo o relato dos mitos. Riobaldo, referindo-se a um de seus personagens, Zé Bebelo, diz: "Tudo quanto falava ficava sendo verdade". É o tempo em que a palavra confunde-se com o objeto que nomeia, em que pronunciar a palavra que designava o demônio ou a divindade era uma temeridade e um perigo. A palavra não tinha um papel mediador: ela era o objeto a que se referia. Mas, segundo Costa Lima, ${ }^{3}$ a esse momento de certeza segue-se um outro, ambíguo, em que se percebe que a palavra não revelava apenas coisas positivas, mas também negativas, como a dor ou o sofrimento. Em seguida, chegase ao ponto em que a palavra não era mais apenas a verdade alethéia - mas também o engano e a persuasão. A palavra e seus detentores perdem o caráter sagrado que tinham. A palavra tornase, verdadeiramente signo, substituindo a relação de verdade com o objeto por um relação de representação, substitutiva, vicária, imperfeita e parcial. De acordo com Peirce, ${ }^{4}$ "um signo representa alguma coisa, seu objeto. Coloca-se no lugar desse objeto, não sob todos os aspectos, mas com referência a um tipo de idéia que tenho, por vezes, denominado o fundamento do representamen." Portanto, há sempre um deslocamento, uma transformação: seja na captura do referente externo (o objeto) pelo signo, seja na produção de um interpretante que é "equivalente ou melhor desenvolvido" que o signo anterior. Por isso, a ciência, a literatura ou a memória não são nunca definitivos. Há sempre um outro signo capaz de retomar e transformar o signo anterior.

Ao tornar-se signo e admitir o engano e a persuasão, ao permitir a retórica, os artifícios, o estilo, a forma, a argumentação, o mascaramento, a linguagem torna-se também mentira, ou seja, não corresponde a nenhum estado real de fatos. Da mesma forma que se estabelecia com seres e coisas uma relação de verdade, agora se

${ }^{3}$ COSTA LIMA, 1980, p. 8-17.

${ }^{4}$ PEIRCE, 1972, p.94. 
refere a seres e coisas que podem não existir. Greimas ${ }^{5}$ exemplifica com a palavra 'quimera' e com a expressão francesa "les papillons ont des oreilles" cujos referentes extra-lingüísticos são criados pela palavra e não antes dela, como estados prévios à linguagem. Ao tornar-se signo e criar seus próprios referentes extra-lingüísticos, a palavra se torna ficcional, ou seja, assume sua capacidade de mentir. Não importa aqui, nem vem ao caso, que a ficção nos faça refletir sobre o mundo e sobre nós mesmos; importa é que ela se constrói como mentira, ou seja, sem corresponder a nenhum estado real de fatos. A literatura não tem que coincidir com o real extra-literário. Caso o fizesse, deveria ter como escopo o documento e não a ficção. Ao afirmar-se como tal aceita receber e transformar a realidade, enriquecendo-se dela e comprometendo-se a recriá-la.

Após a ficção, e tendo-a como seu objeto, vem a crítica. É, como se disse, um sistema semiótico secundário ou terciário, que estabelece com o texto ficcional uma relação intertextual, da mesma forma que o faz com outros textos críticos. Se tomarmos certos autores dentro da literatura brasileira e portuguesa, como Eça de Queiroz, Machado de Assis e Guimarães Rosa, veremos que são objeto de um longo diálogo. No caso de Guimarães Rosa, essa intertextualidade crítica se prolonga por uma listagem de mais de cem páginas, que compreende textos produzidos no exterior e no Brasil. Da mesma forma que o texto ficcional é um signo, também o é o texto crítico. Como tal, submete-se a um processo de transformação permanente, pela interação entre objeto, signo e interpretante, como conceituado por Peirce. Não haverá um texto crítico definitivo, como não haverá um texto ficcional definitivo. Como diz Riobaldo, tudo é muito provisório. Tudo se faz como um jogo entre signos, em permanente dinamismo, alternando suas posições como signos, objetos e interpretantes.

A construção da memória passa pela percepção desse jogo semiótico, dessa rede de referências, pela atualização do sentido que

${ }^{5}$ GREIMAS, 1974, p. 9-25 
é sempre dependente das relações estabelecidas entre os signos e nunca preexistente a elas. Construir a memória, portanto, consiste em modificá-la continuamente. Desse ponto de vista, os museus, as bibliotecas, os dicionários e enciclopédias, todas as coleções de conhecimentos e informações passam a ter sentido e movimento. É necessário, para isso, que haja um olhar que estabeleça novas relações, novos construtos, novos recortes sobre a realidade. Esse olhar, modernamente, só é possível através da tecnologia, pelo computador, que vai tornar a noção de intertexto em hipertexto, e acelerar o processo de produção sígnica descrito acima, tanto por Peirce quanto por Eco. Ainda que todo o processo de conhecimento se faça pelo estabelecimento de relações, atualmente, a diferença, como acentua Pierre Lévy, ${ }^{6}$ é a velocidade com que elas são realizadas. Para ele, um hipertexto é um

conjunto de nós ligados por conexões. Os nós podem ser palavras, páginas, imagens, gráficos ou partes de gráficos, seqüências sonoras, documentos complexos que podem eles mesmos ser hipertextos.

O paradoxo da pesquisa, como dissemos inicialmente, é infletir simultaneamente para o passado e para o futuro. Mas não é o passado que determina o futuro, numa relação mecânica de causa e efeito, mas o futuro que especifica e organiza o passado. Nesse sentido pode-se entender a assertiva de Borges de que cada texto constrói as suas influências. A construção da memória é uma tarefa complexa que deve se manifestar como uma recusa ao passado, à memória como um acervo de lembranças, de imagens estratificadas, de lampejos mais ou menos conscientes. A memória, e sua construção, deve ser vista como signo, ou seja, como linguagem, como falta, como incompletude e, portanto, como possibilidade de reelaboração. Tomá-la como signo significa não vinculá-la a nenhum estado real de fatos, ou seja, significa construí-la também como ficção. Pode-se dizer que para a construção da memória há processos

${ }^{6}$ LÉVY, 1993, p33. 
conscientes e processos inconscientes responsáveis pelos processos de raciocínio como a dedução, a indução ou a abdução, tal como definida por Peirce e empregada por Umberto Eco e Thomas A. Sebeok. ${ }^{7}$ A memória é fruto da nossa construção de um hipertexto, das conexões estabelecidas ou desfeitas, de tudo aquilo que é considerado importante ou desprezível. A memória não se faz, jamais, apenas daqueles fragmentos que são recuperados pelo esforço de rememoração; constitui-se, na maior parte das vezes, por aqueles grandes intervalos que são esquecidos. Em "Nenhum, nenhuma", Guimarães Rosa descreve o trabalho da memória "...como um riachinho, às voltas, que tentasse subir a montanha" e mais à frente, acentuando o esforço para a construção da memória, diz: "Luta-se com a memória". ${ }^{8}$ A metáfora exprime a dificuldade que temos de chegar ao princípio e todas as perdas que há pelo percurso. O trabalho da memória e o da pesquisa que lhe está ligada se relaciona, portanto, a um conjunto de desejos, de propósitos, de intenções, a uma busca por caminhos que a todo momento se bifurcam.

A pesquisa, neste sentido, deve ser vista como um descobrimento de nós e de suas conexões, em toda a complexidade que isto possa trazer. Não importa que tenha havido ou não uma intencionalidade, uma consciência; importa que isso possa ser demonstrado. Por outro lado, essa estrutura revelada pode se transformar a qualquer momento, uma vez que não é permanente, mas depende da demonstração de novas conexões e novos nós. É para isso que servem as pesquisas: para construir a memória e não para serem construídas pela memória. Toda pesquisa deve ter consciência de sua própria falibilidade e de seu perecimento. Deve saber-se apenas uma passagem para um outro estágio, que se espera maior e mais completo. É, como diria Guimarães Rosa, uma travessia.

\footnotetext{
${ }^{7}$ ECO, SEBEOK, 1991.

${ }^{8}$ ROSA, 1967, p. 54, 56.
} 
Há alguns anos, propusemos ao Departamento de Semiótica e Teoria da Literatura da Faculdade de Letras da UFMG uma pesquisa sobre a obra de Guimarães Rosa, cujo título era exatamente "A leitura das leituras", e que deveria consistir num levantamento da crítica publicada sobre Guimarães Rosa, nacional e internacionalmente. Um dos objetivos era o de ler as críticas sobre sua obra, resenhá-las sinteticamente e passá-las para os próximo leitores; outro era o de estabelecer os nós e conexões realizados pelas várias leituras, tentando entender a lógica ou a ilogicidade dessa estrutura que se montou desde 1945, data da publicação de Sagarana, e que se estende até o momento. Só parcialmente esses objetivos foram alcançados, e a própria coleta do material, ainda que se estenda por mais de cem páginas, ficou prejudicada por vários fatores, que vão desde encargos burocráticos até a negação de financiamento. No entanto, coloca-se como um processo cujo término está longe de acontecer, seja pela contínua publicação de textos críticos sobre a obra de Guimarães Rosa, seja pela complexidade que o projeto vem assumindo. O projeto tem duas faces relevantes: primeiro, por ser uma recuperação da memória crítica de um dos mais prestigiados autores da literatura brasileira; segundo, por propor uma leitura semiótica dessa produção crítica, mostrando como ela se articula, estabelecendo um jogo de interpretantes e produzindo sentidos. $\mathrm{O}$ projeto se coloca como uma reflexão, a partir dos conteúdos da teoria literária e da semiótica, sobre a articulação dessa crítica entre si e com as obras rosianas Não interessa apenas a relação entre a crítica e a obra literária, mas também, e principalmente, as leituras que a crítica faz da própria crítica, o trabalho de recortes, de citação, de intertextualidade crítica, as referências teóricas em que a crítica se ampara e sua evolução ao longo do tempo.

O trabalho de pesquisa, que só agora começará a ser publicado, deverá dividir-se em três momentos complementares: o primeiro deverá dar conta dos textos publicados pelo Suplemento Literário do Minas Gerais, desde setembro de 1967, em que surge uma resenha de Laís Correa de Araújo, entitulada "Tutaméia, só?", e a edição especial de 25 de novembro do mesmo ano, feita a partir 
do espanto e da perplexidade com a morte de Guimarães Rosa, até os números publicados em 1998, pelo agora denominado Suplemento. O segundo momento deverá enfocar os trabalhos publicados em revistas, livros e capítulos de livros, cujo número cresceu significativamente nos últimos anos, em que se lembrou do aniversário de publicação de Sagarana, de Grande Sertão: Veredas e de Corpo de Baile, e da data de morte de Guimarães Rosa em que, como ele mesmo caracterizou, passou a "estar encantado". O terceiro momento, e o mais difícil pela diversidade do material e pelo número espantoso de originais, será dedicado à crítica publicada em jornais: do Correio do Porto, em Portugal, ou do Diário Católico, de Belo Horizonte, ao Suplemento Literário do Estado de S. Paulo, ao Caderno JB ou ao Caderno Mais, da Folha de S. Paulo, além de uma infinidade de pequenos jornais do interior do país. Mesmo sem estar previsto, cogita-se num quarto e último volume tratando das teses produzidas sobre o autor. Como a maioria das teses e dissertações fica restrita ao âmbito das bibliotecas das instituições em que foram produzidas, fica difícil o acesso a elas. A dificuldade aumenta quando se sabe que nem todas as monografias têm títulos claros, contendo referências a Guimarães Rosa ou a títulos de sua obra. Todo esse esforço deverá resgatar a memória crítica de um dos maiores autores da Literatura Brasileira e a própria memória da crítica literária brasileira, além de fornecer um material de consulta absolutamente original aos pesquisadores de Guimarães Rosa.

Construir a memória, pela pesquisa, levantando os intertextos e os hipertextos é uma necessidade e um ideal que, nem sempre logramos atingir. É preciso que construamos nossa memória, nossos signos, nossa ficção, seres de palavras que somos. É preciso seguir lutando contra os estereótipos, as estratificações, o costumeiro, o tradicional. Como diz Drummond, "Lutar com palavras/ é a luta mais vã./ Entanto lutamos/ mal rompe a manhã". 


\section{Referências Bibliográficas}

COSTA LIMA, Luiz. Mímesis e modernidade. Rio: Graal, 1980.

DELEUZE, Gilles. Lógica do sentido. Trad. Luiz Roberto S. Fortes. São Paulo: Perspectiva, 1974.

ECO, Umberto. Tratado geral de semiótica. Trad. Antônio de Pádua Danesi, Gilson C.C. de Souza. São Paulo: Perspectiva, 1980.

ECO, Umberto, SEBEOK, Thomas A. Signo de três. Trad. Silvana Garcia. São Paulo: Perspectiva, 1993.

GREIMAS, A. J. L'énnonciation. Significação, Araraquara, n. 1, ago. 1974, p. 9-25

LÉVY, Pierre. As tecnologias da inteligência: o futuro do pensamento na era da informática. Trad. Carlos Irineu da Costa. Rio de Janeiro: Editora 34, 1993.

PEIRCE, Charles Sanders. Semiótica e filosofia. Trad. Octanny Silveira da Mota, Leonidas Hegenberg. São Paulo: Cultrix, 1972.

ROSA, João Guimarães. Primeiras estórias. Rio: José Olympio, 1967.

\section{Resumo}

Este texto propõe uma reflexão sobre a memória como um processo permanente e dinâmico de seleção e de construção de seu próprio conteúdo, na forma de um trabalho semiótico de produção de signos. A pesquisa universitária, ao orientarse para o futuro, consiste também num procedimento de resgate e de construção da memória.

\section{Résumé}

Ce texte propose une réflexion sur la mémoire comme un procédé permanent et dinamique de choix et de construction de son propre contenu, dans la forme d'un travail semiotique de production de signes. La recherche universitaire, dans son orientation vers le future, constitue aussi um procédé pour le rachat et la construction de la mémoire. 